\title{
A Finnish Meteorological Institute-Aerosol Cloud Interaction Tube (FMI-ACIT) : Experimental setup and tests of proper operation
}

\section{Doulgeris, Konstantinos M.}

2018-09-28

Doulgeris , K M , Brus , D , Raatikainen , T \& Kerminen , V-M 2018 , ' A Finnish

Meteorological Institute-Aerosol Cloud Interaction Tube (FMI-ACIT) : Experimental setup and tests of proper operation ' , Journal of Chemical Physics , vol. 149 , no. 12,124201 . https://doi.org/10.1063/1.50372

http://hdl.handle.net/10138/307565

https://doi.org/10.1063/1.5037298

publishedVersion

Downloaded from Helda, University of Helsinki institutional repository.

This is an electronic reprint of the original article.

This reprint may differ from the original in pagination and typographic detail.

Please cite the original version. 


\title{
A Finnish Meteorological Institute-Aerosol Cloud Interaction Tube (FMI-ACIT): Experimental setup and tests of proper operation
}

\author{
Konstantinos M. Doulgeris, ${ }^{1, a)}$ David Brus, ${ }^{1}$ Tomi Raatikainen, ${ }^{1}$ and Veli-Matti Kerminen ${ }^{2}$ \\ ${ }^{1}$ Finnish Meteorological Institute, Erik Palménin Aukio 1, P.O. Box 503, FI-00101 Helsinki, Finland \\ ${ }^{2}$ Institute for Atmospheric and Earth System Research/Physics, Faculty of Science, University of Helsinki, \\ Helsinki, Finland
}

(Received 23 April 2018; accepted 6 September 2018; published online 26 September 2018)

\begin{abstract}
The Finnish Meteorological Institute-Aerosol Cloud Interaction Tube (FMI-ACIT) is a multi-purpose instrument for investigating atmospherically relevant interactions between aerosol particles and water vapor under defined laboratory conditions. This work introduces an experimental setup of FMI-ACIT for investigation of the aerosol activation and the droplet growth under supersaturated conditions. Several simulations and experimental tests were conducted to find out what the proper operational parameters are. To verify the ability of FMI-ACIT to perform as a cloud condensation nuclei (CCN) counter, activation experiments were executed using size selected ammonium sulfate $\left[\left(\mathrm{NH}_{4}\right)_{2} \mathrm{SO}_{4}\right]$ particles in the size range of $10-300 \mathrm{~nm}$. Supersaturations from $0.18 \%$ to $1.25 \%$ were tested by experiments with different temperature gradients. Those showed that FMI-ACIT can effectively measure $\mathrm{CCN}$ in this range. Measured droplet size distributions at supersaturations $0.18 \%$ and $1.25 \%$ are in good agreement with those determined by a droplet growth model. Published by AIP Publishing. https://doi.org/10.1063/1.5037298
\end{abstract}

\section{INTRODUCTION}

Aerosols play an important role in the atmospheric radiation budget; they can absorb or scatter the incoming or outgoing radiation and they have a potential to activate into cloud droplets, i.e., act as cloud condensation nuclei (CCN). The ability of aerosols to act as $\mathrm{CCN}$ is dependent on the supersaturation of water vapor, aerosol size and its chemical composition. ${ }^{1}$ Properties of clouds and their formation processes are poorly understood particularly in mixed phase and ice clouds. ${ }^{2}$

Numerous devices with different set ups were built for measuring CCN. Those devices can be classified into two major categories according to the way they produce water vapor supersaturation, first by using the nonlinear dependence of water vapor pressure upon temperature and second by using the difference between water vapor diffusivity and thermal diffusivity. The first mechanism is widely used in static diffusion chambers $^{3,4}$ and the second mechanism is used in laminar flow chambers. $^{5-8}$

Nenes et al. ${ }^{9}$ made a theoretical analysis of basic cloud condensation nucleus devices which involves both static diffusion chambers and laminar flow diffusion chambers. The original design of a static diffusion chamber was presented by Twomey. ${ }^{3}$ There, two metal parallel plates, one hot and one cold, were placed with their facing surfaces wetted. Sinnarwalla and Alofs ${ }^{10}$ developed the continuous flow parallel metal plate thermal diffusion chamber to avoid some limitations that the static diffusion chamber had. An improvement

\footnotetext{
a) Author to whom correspondence should be addressed: konstantinos. doulgeris@fmi.fi
}

version of the continuous flow parallel metal plate thermal diffusion chamber was introduced by Fukuta and Saxena ${ }^{11}$ where the gradient in temperature was imposed perpendicular to the flow direction so that particles with the same residence time experience different supersaturations along different streamlines. Hudson ${ }^{5}$ modified the continuous flow thermal diffusion chamber and built a dynamic spectrometer which could simulate conditions of a warm cloud and it could be used also in airborne measurements. Chuang et al., ${ }^{12}$ introduced the Caltech spectrometer which used the Hudson method in a flow tube.

During the last couple of decades several attempts have taken place to construct and introduce CCN counter devices with different possibilities and features. Giebl et al. ${ }^{13}$ investigated $\mathrm{CCN}$ activation of oxalic and malonic test aerosols using the University of Vienna cloud condensation nuclei counter which operated on the principle of a static thermal diffusion chamber and could have supersaturations in the range from $0.1 \%$ to $2 \%$. Stratmann et al. ${ }^{6}$ introduced Leipzig Aerosol Cloud Interaction Simulator (LACIS) which was based on a laminar flow tube. Wex et al. ${ }^{14}$ proved that LACIS can perform as CCN detector and is able to measure hygroscopic growth of atmospheric particles. Snider et al. ${ }^{15}$ developed and introduced the Wyoming CCN Instrument, a thermal diffusion cloud chamber. Roberts and Nenes ${ }^{7}$ introduced a cylindrical continuous-flow thermal-gradient diffusion chamber that provides in situ measurements of $\mathrm{CCN}$ and can be operated in airborne measurements for supersaturations from $0.1 \%$ to $3 \%$. This instrument produces supersaturation by establishing a constant streamwise temperature gradient so that the difference in water vapor and thermal diffusivity yields a quasi-uniform centerline supersaturation. Later, Lance et al. ${ }^{16}$ explored fully the possibilities of this instrument by using a 
numerical model. Rose et al. ${ }^{17}$ gave a full description of the measurement uncertainties of the instrument based on calibration experiments $\mathrm{CCN}$ counter using ammonium sulphate and sodium chloride particles and determined the supersaturation using Köhler theory. ${ }^{18}$

Both static diffusion chambers and laminar flow chambers have been also used for other purposes except for measuring CCN. Further investigations were made with several different $\mathrm{CCN}$ counters which were modified in order to investigate ice nucleation. ${ }^{19-21}$ Connolly et al. ${ }^{8}$ introduced a laminar flow tube with larger dimensions (10 $\mathrm{m}$ high, $1 \mathrm{~m}$ diameter) with the ability to measure ice crystals.

In 2001, Lihavainen and Viisanen ${ }^{22}$ built a laminar flow diffusion chamber for studying homogeneous nucleation of $n$-hexanol. Based on their design, we developed an alternative version of the laminar flow diffusion chamber in order to measure ice and cloud droplet formation under defined laboratory conditions. The relatively large dimensions of the Finnish Meteorological Institute-Aerosol Cloud Interaction Tube (FMI-ACIT) setup allows long (tens of minutes) steady state measurements. Our future work will concentrate on testing FMI-ACITs' ability to investigate ice nuclei formation, but in this paper we focus on $\mathrm{CCN}$. The experimental setup of FMI-ACIT is described in detail in Sec. II A. In Secs. II B and II C, a finite element method (femtube 2 model) and a droplet growth model that are used for the comparison with our experimental data are presented. Subsequently, in Sec. III A, operational parameters of FMI-ACIT are investigated and chosen based on the femtube 2 model and several experimental tests. In Sec. III B, experimental $\mathrm{CCN}$ activation tests that characterize our setup are presented. Finally, we compare aerosol growth calculated by the model to that from the experimental tests for two different supersaturations.

\section{METHODS}

\section{A. Experimental setup}

FMI-ACIT is based on the principle of a laminar flow diffusion chamber, ${ }^{22}$ but it shares the design of a laminar flow tube just as used in our previous studies. ${ }^{23,24}$ The experimental setup of FMI-ACIT is presented in Fig. 1. It consists of three main parts: a humidification system (HS), a preheater (PR), and a condenser (C), which are described in the following text. The set values of all the flows and the temperatures of the three main parts were kept constant during each experiment. The temperatures of the humidification system $\left(T_{\mathrm{HS}}\right)$ and preheater $\left(T_{\mathrm{PR}}\right)$ are adjustable and controlled by circulating liquid baths (LAUDA RC $6 \mathrm{CS}$ ), and the temperature of the condenser $\left(T_{\mathrm{C}}\right)$ is adjustable and controlled by another circulating liquid bath (LAUDA Proline RP 1845). The temperatures are measured with six PT100 probes (one in the humidification system, two in the preheater, and four in the condenser). Every part of the FMI-ACIT is insulated from the environment.

Polydisperse aerosol was produced by an aerosol generator (Topas, model ATM226) and subsequently dried with silica-gel dryer. The polydisperse aerosol was then size selected by a differential mobility analyser (DMA, Hauketype, length $0.109 \mathrm{~m}$ ). The DMA was operated with $2.01 \mathrm{~min}^{-1}$ aerosol and $10.01 \mathrm{~min}^{-1}$ sheath and excess air flows. The initial concentration of monodisperse aerosol, before entering the humidification system of the FMI-ACIT, was measured

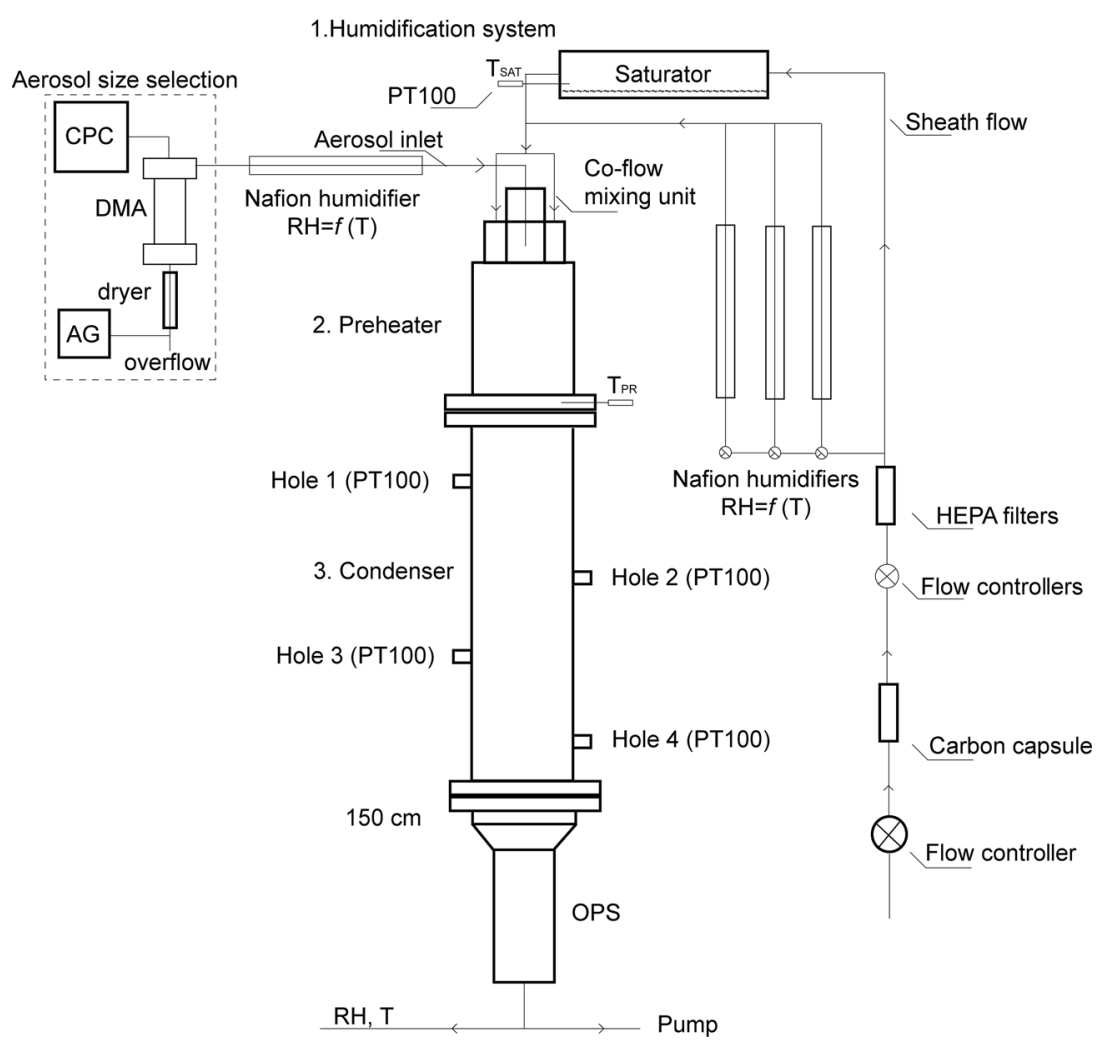

FIG. 1. The experimental setup of FMI-ACIT. AG represents the aerosol generator (Topas, model ATM226), CPC represent the condensation particle counter (CPC, model 3776, TSI, Inc.) and DMA represents the differential mobility analyser (DMA, Hauketype, length $0.109 \mathrm{~m}$ ). The temperatures are measured with six PT100 probes (one in the saturator, one in the preheater, and four in the condenser). OPS represent Optical Particle Sizer (OPS model 3330, TSI, Inc. USA) which is used as a counter in this work. 
by a condensation particle counter (CPC, model 3776, TSI, Inc.).

The humidification system used in the experimental setup of this work consists of one saturator and four nafion humidifiers. One humidifier was placed after the aerosol size selection and the remaining three humidifiers were placed in parallel to the saturator to humidify the sheath flow. The four nafion humidifiers were used only during initial tests and especially at high flow rates $\left(6-101 \mathrm{~min}^{-1}\right)$ in order to ensure that desired supersaturation will be achieved inside the condenser. During the activation experiments (Sec. III B), only one humidifier was used (the one after the aerosol size selection). The saturator is a horizontal iron tube with a Teflon insert having an inner diameter, I.D ID $=5 \mathrm{~cm}$ and length $\mathrm{L}=1 \mathrm{~m}$. A steady flow of purified and particle free air was introduced to the humidification system using ultrapure milli$\mathrm{Q}$ water (resistivity $18.2 \mathrm{M} \Omega \mathrm{cm} @$ at $25^{\circ} \mathrm{C}$ ). The air runs through a set of high efficiency particle absorbers (HEPA filters, Pall Corp.) and active carbon capsules (Pall Corp.) before entering the saturator/humidifiers. The temperature of the humidification system controls the amount of vapor in the air flow. All humidifiers and the saturator were set to the same temperature.

Aerosol enters the preheater from the humidification system through the stainless steel tube I.D. ID $=4 \mathrm{~mm}$ and length (inside the preheater) $=5 \mathrm{~cm}$. Preheater is a stainless steel cylinder and has I.D. ID $=6 \mathrm{~cm}$ and $\mathrm{L}=0.5 \mathrm{~m}$. The sheath flow enters the preheater via a Teflon part having ports of I.D. ID $=1 \mathrm{~mm}$. The ports were drilled in as concentric circles with $1 \mathrm{~cm}$ gap around the aerosol inlet and $1 \mathrm{~cm}$ from the flow tube preheater wall. The total flow inside the flow tube is combined aerosol and sheath flow. Those are kept constant with a mass flow controller to within $\pm 3 \%$ (MKS type 250). The sheath flow was measured continuously with a mass-flow meter (model 4043, TSI, Inc.) placed before the humidification system and the aerosol flow was measured before and after every run with a bubble flow meter (Gilian Gilibrator2 air flow calibrator, Sensidyne) placed after the DMA and before the flow enters the nafion humidifier. The temperature of the preheater was set always higher $\left(\sim 1^{\circ}\right)$ than the temperature of the humidification system in order to stabilize the flow and avoid condensation in the top section of the flow tube.

The condenser is a stainless steel cylinder and has I.D. $\mathrm{ID}=6 \mathrm{~cm}$ and $\mathrm{L}=1 \mathrm{~m}$. Both the preheater and the condenser are installed vertically to avoid gravitational settling of the particles. The connection between preheater and condenser was insulated to make as steep temperature change as possible and thus create supersaturation at well-defined conditions. Thermal separation was made with a Teflon insulator with a thickness of $2 \mathrm{~cm}$ and I.D. ID $=6 \mathrm{~cm}$. Figures 2(a) and 2(b) demonstrate typical profiles of temperature and saturation ratio inside the condenser using conditions from the experimental measurements. The conditions used for the simulations were $T_{\mathrm{HS}}=299.00 \mathrm{~K}, T_{\mathrm{PR}}=300.00 \mathrm{~K}, T_{\mathrm{C}}=281.00 \mathrm{~K}$, and $Q_{\text {tot }}=2.01 \mathrm{~min}^{-1}$. The higher saturation ratio was first reached close to the wall since the flow started to cool from the wall toward the centerline. This is because the rate of heat transfer by conduction is lower than the rate of mass transfer by molecular diffusion. ${ }^{25}$ Saturation ratios inside the condenser centerline range from 0.94 to 1.1 . This is because the rate of heat transfer by conduction is lower than the rate of mass transfer by molecular diffusion. ${ }^{25}$ The temperature of the condenser had a drop in its first $20 \mathrm{~cm}$. After the first $20 \mathrm{~cm}$ of the condenser, the mixture in the centerline reached the same temperature with the tube walls. Figure 2(c) represents both the saturation ratio and the temperature along the centerline of the condenser. Saturation ratio increased sharply from sub-saturated conditions to supersaturated conditions (saturation ratio higher than 1). After this sharp increase, the saturation ratio reached its maximum value (around $20 \mathrm{~cm}$ from the beginning of the condenser) and decreased slowly to the saturation ratio of 1 . The saturation ratio during this simulation example reached a maximum value of 1.013 along the centerline. The full description of the model used for the simulation is presented in Sec. II B.

Particles are injected to the preheater close to the centerline so that they have similar relative humidity history and residence time and also to avoid wall losses. Ideally, every single particle would be travelling only along the centerline of the preheater and the condenser, but in reality some particles traveled through regions with different saturation ratios.

An Optical Particle Sizer (OPS model 3330, TSI, Inc. USA) which detects particles in the range $0.3-10 \mu \mathrm{m}$ was used as a counting system and it was connected to the end of the condenser. The OPS was modified in a way that the OPS pump was bypassed and the flow tube total flow passed through the OPS counting chamber, and the raw counts were corrected accordingly.

\section{B. Finite element method tube2 model description}

The saturation ratio and the temperature profiles inside the condenser of the FMI-ACIT cannot be measured experimentally. For that reason, we adopted the existing finite element method tube 2 (femtube 2) model, which is described in detail in the study of Lihavainen. ${ }^{26}$

The model solves five coupled differential equations, heat and mass transfer, equations of motions, and an equation of continuity to simulate the flows inside the condenser. However, in order to simplify these equations, several assumptions were made. These are that the equations can be solved in a steady state, the effect of radial velocity is negligible and set to zero, and the flow is incompressible. The simplifications of the equations of motion lead to a simple problem that was analytically solved and produced a parabolic lateral velocity profile. ${ }^{27}$ The boundary conditions for the heat and mass transfer equations are

$$
\begin{aligned}
T\left(r, z=z_{0}\right) & =T_{P R}, \\
T\left(R_{0}, z_{0}<z \leq 0\right) & =T_{P R}, \\
T\left(R_{0}, z>0\right) & =T_{C}, \\
\omega\left(r, z=z_{0}\right) & =\omega_{e q}\left(T_{H S}\right), \\
\omega\left(R_{0}, z_{0}<z \leq 0\right) & =\omega_{e q}\left(T_{H S}\right), \\
\omega\left(R_{0}, z>0\right) & =\omega_{e q}\left(T_{C}\right),
\end{aligned}
$$



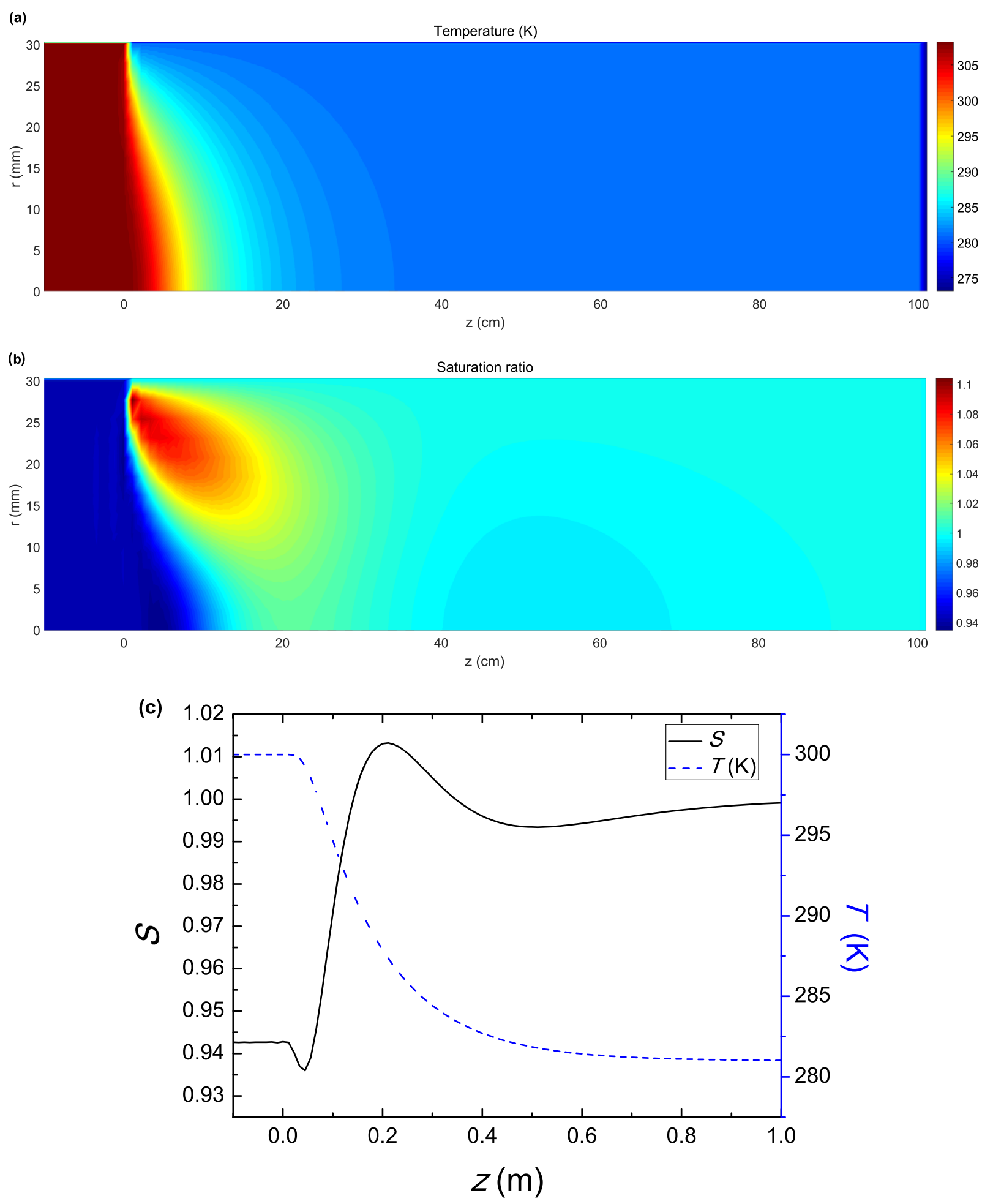

FIG. 2. Simulated profiles of (a) the temperature and (b) the saturation ratio inside the FMI-ACIT where the $y$-axis and x-axis represents the radial and lateral coordinates of the condenser. (c) Details of temperature $(T)$ and the saturation ratio $(S)$ along the center line of the condenser as calculated with the femtube 2 model. Temperatures of the humidification system, the preheater, and the condenser were set as 299.00, 300.00, and $281.00 \mathrm{~K}$, respectively. The total flow rate inside the condenser was $21 \mathrm{~min}^{-1}$ and the flow direction is from left to right.

where $T_{\mathrm{PR}}$ is the temperature of the preheater, $T_{\mathrm{C}}$ is the temperature of the condenser, $T_{\mathrm{HS}}$ is the temperature of the humidification system, and $R_{0}$ is the radius of the tube. Additionally, $\omega_{\mathrm{eq}}\left(T_{\mathrm{HS}}\right)$ is the mass fraction of water vapor defined by the saturation vapor pressure at the temperature $T_{\mathrm{HS}}, \omega_{\mathrm{eq}}\left(T_{\mathrm{C}}\right)$ is the mass fraction of water vapor defined by the saturation vapor pressure at the temperature $T_{C}, z=0$ is the boundary point between the preheater and the condenser, and $z_{0},-10 \mathrm{~cm}$, is a chosen starting point of calculations in the preheater. The first boundary condition in Eq. (1) sets the temperature at $\mathrm{z}_{0}$ to that of the preheater. The second boundary condition in Eq. (2) sets the temperature of the wall between the starting 
point of the calculation, $\mathrm{z}_{0}$, and the boundary between the preheater and the condenser, $z=0$. The third boundary condition in Eq. (3) sets the temperature at the wall of the condenser. The fourth boundary condition in Eq. (4) sets the mass fraction profile across the tube at $z_{0}$ to the value defined by the equilibrium vapor pressure at the temperature of the saturator. The fifth boundary condition in Eq. (5) sets the mass fraction of the vapor at the wall between $z_{0}$ and $z$ to the same value as the fourth boundary condition. The sixth boundary condition in Eq. (6) sets the mass fraction at the wall of the condenser to the value defined by the equilibrium vapor pressure at the temperature of the condenser wall. As a binary diffusion coefficient $\left(D_{\mathrm{AB}}\right)$, we used the most common expression based on both theory and interpolation of experimental data by Hall and Pruppacher. $^{28}$

The simulation based on the Eulerian equations provides us profiles of the temperature $(T)$ and saturation ratio $(S)$ inside the preheater and the condenser. Boundary conditions for the simulations that are presented in this study were set to match the values of the experimental conditions. These parameters are the temperature of the walls of the preheater and the condenser, the temperature of the laboratory which was measured directly, the total flow rate inside the flow tube, the atmospheric pressure and the dimensions of the flow tube.

\section{Droplet growth model}

To describe the growth of the particles inside the flow chamber, we used the droplet growth model as described in detail in Raatikainen et al. ${ }^{29}$ The rate of the change of the droplet size is described by the differential growth equation, ${ }^{30,31}$

$$
D_{p} \frac{d D_{p}}{d t}=\frac{S-S_{e q}}{\frac{\rho_{w} R T_{\infty}}{4 p^{o}\left(T_{\infty}\right) D_{u}^{\prime} M_{w}}+\frac{\Delta H_{u} \rho_{w}}{4 k_{a}^{\prime} T_{\infty}}\left(\frac{\Delta H_{u} M_{w}}{T_{\infty} R}-1\right)},
$$

where $D_{p}$ is the droplet diameter, $S$ and $S_{e q}$ are ambient and droplet water equilibrium saturation ratios, $\rho_{w}$ is the water density, $M_{w}$ is the molar mass of water, $T_{\infty}$ is temperature of the environment, $p^{o}\left(T_{\infty}\right)$ is water saturation vapor pressure at temperature of the environment, and $\Delta H_{u}$ is the water vaporization enthalpy. Equation (7) is considered as an initial value problem where temperature and water vapor saturation ratio depend on time or on the location of the droplet in the flow tube. The femtube 2 model was used to generate supersaturation and temperature profiles inside the flow tube as described in Sec. II B, and the droplet velocity was calculated from the total flow rate while assuming a parabolic lateral velocity profile.

Equation (7) contains $D_{u}^{\prime}$ which is the diffusivity of water and the $k_{a}^{\prime}$ which is the thermal conductivity of air that account for non-continuum effects, ${ }^{31}$

$$
\begin{aligned}
D_{u}^{\prime} & =\frac{D_{u}}{1+\frac{2 D_{u}}{a_{c} D_{p}} \sqrt{\frac{2 \pi M_{w}}{R T_{\infty}}}}, \\
k_{a}^{\prime} & =\frac{k_{a}}{1+\frac{2 k_{a}}{a_{T} D_{p} \rho_{a} c_{p}} \sqrt{\frac{2 \pi M_{a}}{R T}}},
\end{aligned}
$$

where $D_{u}$ is the diffusivity of water vapor in air, $a_{c}$ is the condensation coefficient, $M_{a}$ is the average molar mass of air, $k_{a}$ is the thermal conductivity of air, $\rho_{a}$ is the density of air, $c_{p}$ is the heat capacity of air, and $a_{T}$ is the thermal accommodation coefficient.

For the calculation of the water equilibrium saturation ratio of the growing droplets, Köhler theory is used, ${ }^{17}$

$$
S_{e q}=a_{w} \exp \left(\frac{4 \sigma M_{w}}{R T_{\infty} \rho_{w} D_{p}}\right),
$$

where $\sigma$ is the surface tension and $a_{w}$ is the Raoult term and it is calculated following the kappa-Köhler approach ${ }^{32,33}$

$$
a_{w}=\left(1+\frac{\kappa}{\left(D_{p} / D_{d r y}\right)^{3}-1}\right)^{-1},
$$

where $D_{d r y}$ is the dry diameter of the particle and $\kappa$ is a single solute hygroscopicity parameter.

All the parameters of the droplet growth model are presented in the supplementary material in Tables SI-SIII.

\section{RESULTS}

All the FMI-ACIT experiments were made at the Finnish Meteorological Institute, Helsinki, Finland. First, we present which were the best operational parameters (flow rate and temperatures) of the flow tube by modifying initial parameters for femtube 2 model simulations. To verify the best flow rate found by the simulations, an experimental particle transmission efficiency test was also conducted. All these findings are presented in Sec. III A. Then, to test the functionality of FMIACIT as a CCN counter device, several CCN experiments were conducted using the best operational parameters. We injected size-selected ammonium sulfate $\left[\left(\mathrm{NH}_{4}\right)_{2} \mathrm{SO}_{4}\right]$ particles into the flow tube at different supersaturations. Our experimental results are presented in Sec. III B and show that FMI-ACIT can perform as a $\mathrm{CCN}$ counter.

\section{A. Operational characteristics of the FMI-ACIT}

The parameters and the conditions of this experimental setup can be modified to achieve different levels of saturation ratios. Several simulations and numerous experimental tests were made to investigate and verify the most suitable operational conditions for the FMI-ACIT.

First, we explored which is the most suitable total flow rate, i.e., the sum of the sheath and the aerosol flow rates. Using the femtube 2 model, we investigated the behavior of the saturation ratio $(S)$ and the temperature along the center line of the condenser. The following temperature conditions $\left(T_{\mathrm{HS}}=299.00 \mathrm{~K}, T_{\mathrm{PR}}=300.00 \mathrm{~K}\right.$, and $\left.T_{\mathrm{C}}=281.00 \mathrm{~K}\right)$ were used for the simulations and the total flows were changed from 0.5 to 1.0 and then up to $10.01 \mathrm{~min}^{-1}$ with steps of $1.01 \mathrm{~min}^{-1}$.

Figures $\mathrm{S} 1$ and $\mathrm{S} 2$ present the saturation ratio and temperature of the condenser, respectively, for four different flow rates; see the supplementary material for details. Knowing that the aerosol is injected close to the centerline, Figs. 3(a) and 3(b) show these parameters along the centerline of the 
(a)

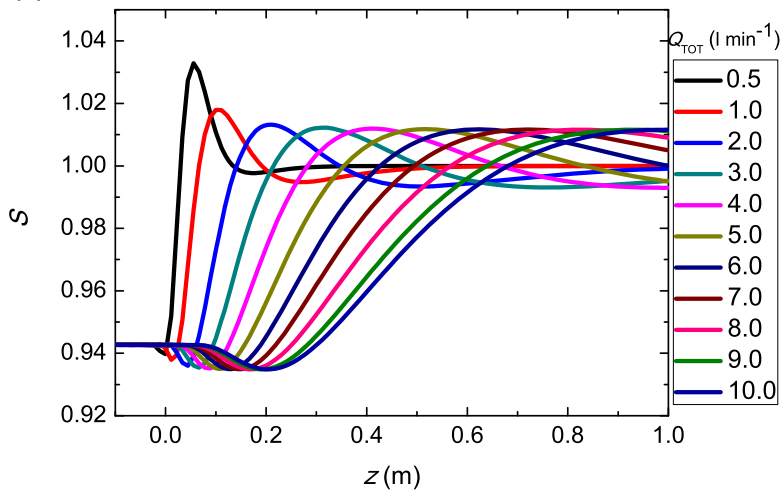

(b)



FIG. 3. Details of (a) the saturation ratio $(S)$ and (b) the temperature along the centerline of the condenser (TC) as calculated with the femtube 2 model for different total flow rates $\left(Q_{\mathrm{TOT}}\right)$. Conditions for the simulations were $T_{\mathrm{HS}}=299.00 \mathrm{~K}, T_{\mathrm{PR}}=300.00 \mathrm{~K}$, and $T_{\mathrm{C}}=281.00 \mathrm{~K}$.

condenser for all the studied flow rates. Figure 3(a) shows that by increasing the total flow rate, the location of the maximum saturation ratio moved further along the centerline of the condenser. For total flow rates higher than $3.01 \mathrm{~min}^{-1}$, the maximum saturation ratio was observed after $0.4 \mathrm{~m}$ along the centerline of the condenser. For flows higher than $2.01 \mathrm{~min}^{-1}$, there was no change in the maximum saturation ratio along the tube centerline, but these maximum saturation ratios were lower than those for 0.5 and $1.01 \mathrm{~min}^{-1}$ flow rates. In this particular example, the maximum saturation ratio increases from a value of 1.013 for the total flow rate of $2.01 \mathrm{~min}^{-1}$ to values of 1.017 and 1.030 for total flow rates of $1.01 \mathrm{~min}^{-1}$ and $0.51 \mathrm{~min}^{-1}$, respectively. Finally, Fig. 3(b) indicates that for total flow rates higher than $3.01 \mathrm{~min}^{-1}$, the temperature of the condenser along its centerline did not have enough time to reach the temperature of the condenser wall.

In addition to the simulations that were performed, an experimental transmission efficiency test was done to quantify the particle losses using six different total flow rates. During this test, temperatures of the humidification system, preheater, and condenser were kept constant $\left(T_{\mathrm{HS}}=299.00 \mathrm{~K}\right.$, $T_{\mathrm{PR}}=300.00 \mathrm{~K}$, and $T_{\mathrm{C}}=281.00 \mathrm{~K}$ ) and total flow rates of $1.0,2.0,3.0,5.0,8.0$, and $101 \mathrm{~min}^{-1}$ were set inside the condenser. Monodisperse ammonium sulfate particles with the sizes of 100, 200, and $300 \mathrm{~nm}$ were used since these particles should be activated at the supersaturations predicted by the femtube 2 model. The number concentration of monodisperse dry aerosols (between 400 and $750 \mathrm{~cm}^{-3}$ ) was continuously measured at the beginning of the humidification system and droplets were continuously measured at the end of the condenser (between 150 and $745 \mathrm{~cm}^{-3}$ ). Their ratio produced the counting efficiency for each total flow rate; the results are presented in Fig. 4 as a penetration through the flow tube as a function of the total flow rate.

Using both simulations and the experimental particle transmission efficiency test, it seems that the FMI-ACIT performs the best at total flow rates between 1 and $31 \mathrm{~min}^{-1}$. At lower total flow rates $\left(<11 \mathrm{~min}^{-1}\right)$ the particles grow to bigger sizes, but they could be lost to the wall due to slow flow. At higher total flow rates $\left(>31 \mathrm{~min}^{-1}\right)$, it takes relatively long for the temperature of the flow to stabilize and reach the condenser wall temperature. As a result, the particles do not experience high enough supersaturation to be activated. The OPS can register particles larger than $300 \mathrm{~nm}$, but its counting efficiency is only $\sim 50 \%$ at that size.

Every further operation tests in this work were made using the total flow rate of $2.01 \mathrm{~min}^{-1}$ with the resulting Reynolds number around 30, i.e., the flow inside the flow tube was laminar. Residence time, which is the time for particles to travel through the condenser along the centerline, for total flow of $\sim 2.01 \mathrm{~min}^{-1}$ was $\sim 50 \mathrm{~s}$.

\section{B. FMI-ACIT as a CNN counter}

After we completed the characterization of the flow tube, we used the most suitable parameters as Sec. III A suggested and tested the FMI-ACIT setup as a CCN counter by performing a series of experiments. Monodisperse ammonium sulfate $\left[\left(\mathrm{NH}_{4}\right)_{2} \mathrm{SO}_{4}\right]$ aerosol was produced and used for every test that was conducted. Purified, particle free air was used as a carrier gas and a total flow rate of $2.01 \mathrm{~min}^{-1}$ was used for the experiments as the simulation and the flow rate transmission

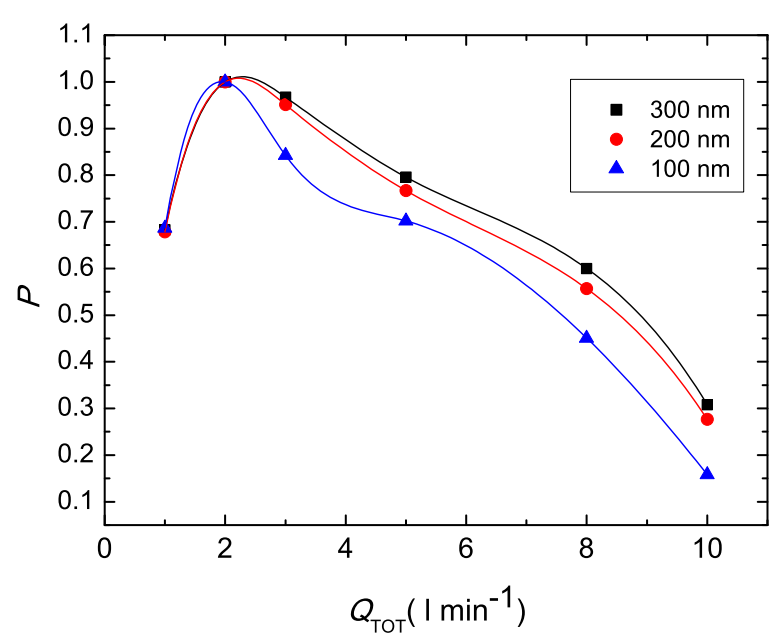

FIG. 4. Particle penetration efficiencies $(P)$ as a function of total flow rate ( $Q_{\text {TOT }}$ ) for 100,200 , and $300 \mathrm{~nm}$ particles. Conditions for the tests were $T H S$ $=299.00 \mathrm{~K}, T \mathrm{PR}=300.00 \mathrm{~K}$, and $T \mathrm{C}=281.00 \mathrm{~K}$. According to the femtube 2 model, maximum supersaturation along the centerline of the condenser range from $1.70 \%$ to $1.10 \%$. Solid lines are interpolation curves and they were made were made just to lead readers' eyes. 



FIG. 5. (a) Activated fraction $(A F)$ versus dry diameter $\left(D_{\mathrm{p}}\right)$ of ammonium sulfate particles for each $\Delta T$. Nonlinear curve fit was calculated using the sigmoidal dose response function. (b) Maximum supersaturation as it was simulated using the femtube 2 model and experimental supersaturation (\%) versus the temperature of humidification system. $\Delta T$ (difference between the temperature of the humidification system and the condenser) is also provided.

efficiency test suggested. All measurements were performed at ambient atmospheric pressure $(\sim 1 \mathrm{~atm})$. The sheath flow rate was measured continuously during the experiments using a mass-flow meter (model 4043, TSI, Inc.). The aerosol flow rate was measured and checked both at the beginning and the end of each measurement using a bubble flow meter (Gilian Gilibrator-2 air flow calibrator, Sensidyne). A sheath to aerosol flow ratio of $8( \pm 0.2)$ inside the condenser was used during all the experimental tests.

Activation of ammonium sulfate particles was measured for six humidification system and condenser temperature differences $(\Delta T): 18.00,17.50,17.25,17.00,16.75$, and $16.50 \mathrm{~K}$. Every $\Delta T$ yielded a different supersaturation inside the condenser as described below.

Dry ammonium sulfate particles with diameters ranging from 10 to $300 \mathrm{~nm}$ were used in each measurement. From 10 to $30 \mathrm{~nm}$, we used step of $5 \mathrm{~nm}$, from 30 to $100 \mathrm{~nm}$, step of $10 \mathrm{~nm}$ and last three sizes were 150, 200, and $300 \mathrm{~nm}$. Each size that was injected inside the preheater was measured for $7 \mathrm{~min}$. After that, we were waiting until OPS showed zero particle counts and then we were waiting five more minutes to ensure that the tube did not contain any particles. We repeated the same procedure for the following size until we obtained the full size

TABLE I. FMI-ACIT temperature gradients along with $D_{50}$ and supersaturation during our experiments. $T_{H S}$ is the temperature of the humidification system, $T_{P R}$ is the temperature of the preheater, and $T_{C}$ is the temperature of the condenser. $D_{50}$ was determined as the dry diameter for which activated fraction of particles reach $50 \% . \Delta \mathrm{T}$ is the humidification system and condenser temperature difference. $S S_{\exp }(\%)$ is the experimental supersaturation inside the condenser and $S S_{\text {mod }}$ is the maximum supersaturation along the centerline of the condenser as predicted by the femtube 2 model.

\begin{tabular}{lcccccc}
\hline \hline $\begin{array}{l}T_{\mathrm{HS}} \\
(\mathrm{K})\end{array}$ & $\begin{array}{c}T_{\mathrm{PR}} \\
(\mathrm{K})\end{array}$ & $\begin{array}{c}T_{\mathrm{C}} \\
(\mathrm{K})\end{array}$ & $\begin{array}{c}\Delta T \\
(\mathrm{~K})\end{array}$ & $\begin{array}{c}D_{50} \\
(\mathrm{~nm})\end{array}$ & $\begin{array}{c}S S_{\exp } \\
(\%)\end{array}$ & $\begin{array}{c}S S_{\text {mod }} \\
(\%)\end{array}$ \\
\hline 299.00 & 300.00 & 281.00 & 18.00 & 25.25 & 1.25 & 1.30 \\
298.50 & 299.50 & 281.00 & 17.50 & 30.35 & 0.94 & 0.92 \\
298.25 & 299.25 & 281.00 & 17.25 & 32.90 & 0.78 & 0.71 \\
298.00 & 299.00 & 281.00 & 17.00 & 43.90 & 0.53 & 0.52 \\
297.75 & 298.75 & 281.00 & 16.75 & 62.30 & 0.31 & 0.34 \\
297.50 & 298.50 & 281.00 & 16.50 & 87.00 & 0.18 & 0.16 \\
\hline \hline
\end{tabular}

range. Next step was to let the FMI-ACIT dry and purify at elevated temperature ( $\sim 303 \mathrm{~K})$ overnight. Next day, when the tube was completely dry and clean, we repeated the same cycle for the same conditions to confirm the reproducibility of our measurements.

From these experimental measurements, we calculated two main values to test that FMI-ACIT is able to work as a CCN counter; activated fraction and growth of the activated particles.

First, the activated fraction was defined as $C_{\mathrm{A}, \mathrm{END}} / C_{\mathrm{A}, \mathrm{INIT}}$, where $C_{\mathrm{A}, \mathrm{END}}$ is the concentration of activated aerosol at the end of FMI-ACIT measured by the OPS and $C_{\mathrm{A}, \mathrm{INIT}}$ is the initial concentration of aerosol before entering the preheater measured by the CPC. For the calculation of $C_{\mathrm{A}, \mathrm{END}}$, we eliminated the first three bins of the OPS counter representing sizes below $0.65 \mu \mathrm{m}$. This choice was made due to noisy counts caused by instruments artifacts independent on any flow tube operational parameter. This resulted in slightly underestimated values of $C_{\mathrm{A}, \mathrm{END}}$. For every set of dry sizes, a sharp increase of the activated fraction occurs and an activated fraction curve was produced by fitting to our experimental data. Figure 5(a) presents the six obtained activation curves. Higher values of $\Delta T$ produced higher values of $S S$ through the centerline of the condenser. For larger particles, the activated fraction increased

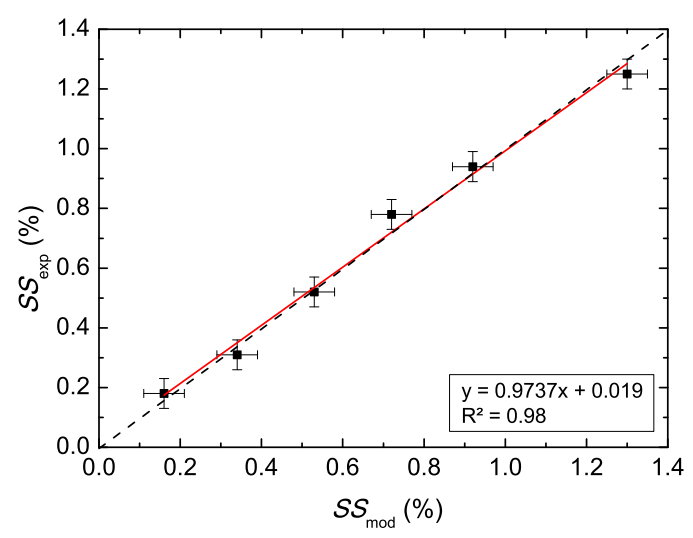

FIG. 6. Experimental supersaturation versus model predicted maximum supersaturation $(\%)$. The red line represents a 1-1 line and the blue line represents linear fit to the six points. 

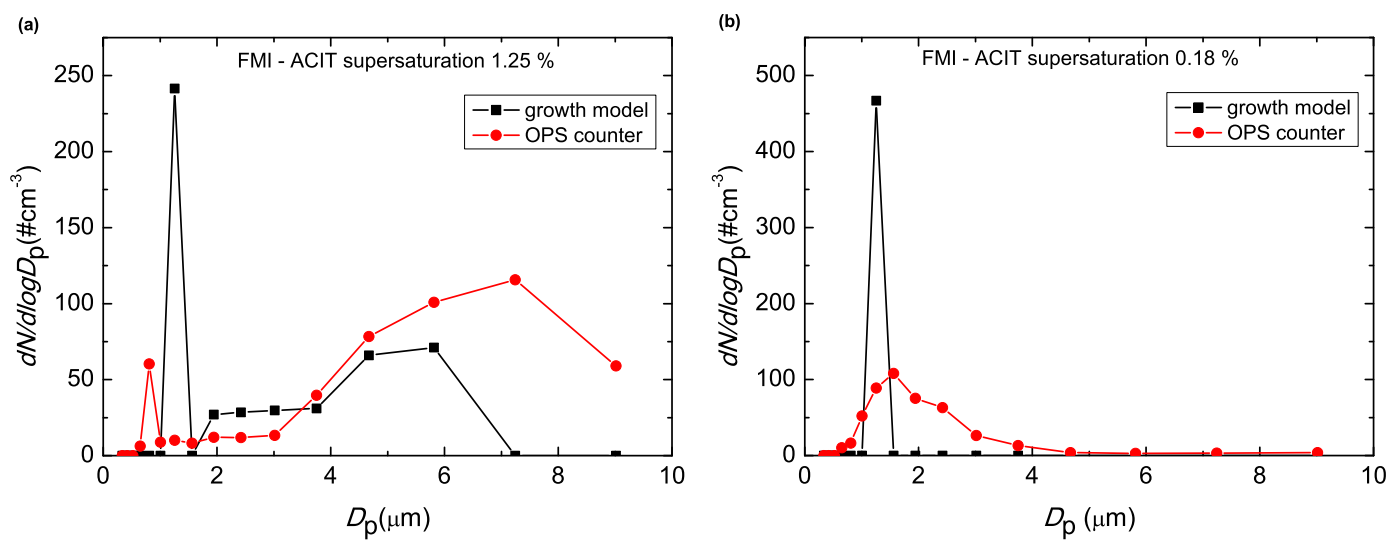

FIG. 7. Predicted and measured droplet size distributions for supersaturation of $1.25 \%$ and $0.18 \%$. The difference between predicted and measured sizes indicates that some particles were travelling through different supersaturations.

and approached the average value 0.91 with standard deviation of 0.11 . In order to obtain the experimental supersaturation $\left(S S_{\text {exp }}\right),{ }^{33} D_{50}$ diameter was found from each activated fraction curve. $D_{50}$ was determined as the dry diameter for which activated fraction of particles reached 50\%. Finally, using the particle size at $50 \%$ activated fraction and the temperature of the condenser, the experimental supersaturation inside the condenser was calculated from the Köhler theory, ${ }^{17,32}$ as shown in Eq. (10). Table I shows the temperature gradients that were used in this work, $D_{50}$ values, and the six different $S S_{\text {mod }}$ and $S S_{\exp }$ inside the condenser. $S S_{\text {mod }}$ is the maximum supersaturation along the centerline of the condenser as predicted by the femtube 2 model. Figure 5(b) shows the modeled and the experimental supersaturations for each $\Delta T$. In the text below, we refer to each experiment using the experimental supersaturation $\left(S S_{\text {exp }}\right)$.

A comparison of the model predicted and experimental supersaturations is presented in Fig. 6. A linear fit based on these six points is presented and shows very good agreement between the two supersaturation values $\left(R^{2}=0.98\right)$. Standard deviation for each point is a result of four experiments conducted at the same conditions in order to prove the reproducibility of our results.

At lower supersaturation inside the tube $(<0.4 \%)$ doubly charged particles were noticed for dry diameters from 10 to $50 \mathrm{~nm}$. Figure S3 shows two activated fraction curves for two different supersaturations lower than $0.4 \%$; see the supplementary material for details. DMA selects particles of one mobility but they are not all singly charged. This leads to the case that there are particles with the same mobility but some of them are slightly larger. Because of their larger diameter, the doubly charged particles activate at a lower supersaturation than the singly charged particles of the same electrical mobility. Doubly charged particles produced a small increase in activated fraction for sizes lower than $50 \mathrm{~nm}$ in both cases. For the analysis of the activated fraction curve in order to find the particle size at $50 \%$, counts of doubly charged particles were determined and subtracted from $N_{\mathrm{ccn}} / N_{\mathrm{cn}}$, as described in Frank et al. ${ }^{34}$

The second factor that was investigated was the growth of activated aerosol. To evaluate the particle growth, a comparison of the measured and modeled (Sec. II C) size distribution for $200 \mathrm{~nm}$ ammonium sulfate particles was done. In Figs. 7(a) and 7(b), we present the modeled and measured size distribution for supersaturations $1.25 \%$ and $0.18 \%$. We calculated the size of the droplets using the centerline saturation ratio profiles that are shown in Fig. 3(a). Time coordinates that are needed to solve the droplet growth equation was calculated from the lateral coordinate by using the known centerline flow velocity. For simplicity, we refer to those profiles with their maximum supersaturation SS. An assumption of the model is that all the particles have exactly the same dry size and they are travelling in a narrow region close to the centerline of the condenser, which is calculated based on the sheath-toaerosol flow ratio and the instrument dimensions. This results in a narrow droplet size distribution. However as we can see in both figures, some particles obviously travel through the regions with slightly different supersaturations. This resulted in a wider size distribution counted by the OPS. For example, for supersaturation of $0.18 \%$ inside the FMI-ACIT, the model predicts that $200 \mathrm{~nm}$ particles will grow to $1.4 \mu \mathrm{m}$. However, during measurements the same particles grew to different sizes and produced a wider size distribution with the mode droplet size of $1.8 \mu \mathrm{m}$.

\section{CONCLUSIONS}

In this work, we have presented and introduced an experimental setup of a laminar flow tube, the Finnish Meteorological Institute-Aerosol Cloud Interaction Tube (FMI-ACIT), that can measure the activation and subsequent growth of aerosols under defined laboratory conditions. FMI-ACIT was built in the Finnish Meteorological Institute and the goal was to find and verify the optimal operational characteristics of this experimental setup. First, a full characterization of the setup was made. The set of optimal working parameters for the proper operation of the FMI-ACIT were chosen using a combination of model simulations and experimental tests. Finally, further experiments were made to test if FMI-ACIT could be operated as a cloud condensation nuclei $(\mathrm{CCN})$ counter.

Model simulations and the experimental tests showed that total flow rates between 1 and $31 \mathrm{~min}^{-1}$ are the best for the operation of the FMI-ACIT. At lower flow rates $\left(<11 \mathrm{~min}^{-1}\right)$ and at higher flow rates $\left(>31 \mathrm{~min}^{-1}\right)$, we faced particle losses 
(>30\%). Therefore, $2.01 \mathrm{~min}^{-1}$ flow rate was used for all further tests that have been made in this study.

In order to test our setups' ability to count $\mathrm{CCN}$, different sizes of monodisperse particles of ammonium sulfate $\left[\left(\mathrm{NH}_{4}\right)_{2} \mathrm{SO}_{4}\right]$ were used to determine supersaturation inside the flow tube. The comparison of the experimental supersaturation with those from the simulations showed good agreement and proved that FMI-ACIT was able to count activated particles of ammonium sulfate for supersaturations in the range from $0.18 \%$ to $1.25 \%$. Finally, we compared the observed droplet size distributions with those predicted by a droplet growth model. Results showed that the observed size distributions are wider at supersaturations of $0.18 \%$ and $1.25 \%$, which indicates that particles in this experimental setup experienced a more variable supersaturations than considered by the model.

It can be concluded that FMI-ACIT functionality to measure the activation and the growth of ammonium sulfate particles in supersaturations ranging from $0.18 \%$ to $1.25 \%$ was tested successfully. Future work will concentrate on low temperature measurements that are needed to test the setups' ability to measure ice nuclei.

\section{SUPPLEMENTARY MATERIAL}

See supplementary material for profiles of the saturation ratio and temperature inside the FMI-ACIT condenser as function of different flow rates. Doubly charged particles for low supersaturations are also presented.

\section{ACKNOWLEDGMENTS}

This work was financially supported by the Academy of Finland Center of Excellence programme (Grant No. 307331) and the KONE foundation.

${ }^{1}$ U. Dusek, G. P. Frank, L. Hildebrandt, J. Curtius, J. Schneider, S. Walter, D. Chand, F. Drewnick, S. Hings, D. Jung, S. Borrmann, and M. O. Andreae, Science 312, 1375 (2006).

${ }^{2}$ J. E. Penner, M. Andreae, H. Annegarn, L. Barrie, J. Feichter, D. Hegg, A. Jayaraman, R. Leaitch, D. Murphy, J. Nganga, and G. Pitari, Report to Intergovernmental Panel on Climate Change From the Scientific Assessment Working Group (WGI), edited by J. T. Houghton, Y. Ding, D. J. Griggs, M. Noguer, P. J. Van der Linden, X. Dai, K. Maskell, and C. A. Johnson (Cambridge University Press, 2001), pp. 289-416.

${ }^{3}$ S. Twomey, J. Rech. Atmos. 1, 101 (1963).

${ }^{4}$ J. L. Katz, J. Chem. Phys. 52, 4733 (1970).
${ }^{5}$ G. J. Hudson, J. Atmos. Oceanic Technol. 6, 1055 (1989).

${ }^{6}$ F. Stratmann, A. Kiselev, S. Wurxler, M. Wendisch, and J. Heintzenberg, J. Atmos. Oceanic Technol. 21, 876 (2004).

${ }^{7}$ G. C. Roberts and A. Nenes, Aerosol Sci. Technol. 39, 206 (2005).

${ }^{8}$ P. J. Connolly, C. Emersic, and P. R. Field, Atmos. Chem. Phys. 12, 2055 (2012).

${ }_{9}^{9}$ A. Nenes, P. Y. Chuang, R. C. Flagan, and J. H. Seinfeld, J. Geophys. Res. 106(D4), 3449, https://doi.org/10.1029/2000jd900614 (2001).

${ }^{10}$ A. Sinnarwalla and D. Alofs, J. Appl. Meteorol. 12, 831 (1973).

${ }^{11}$ N. Fukuta and V. Saxena, J. Appl. Meteorol. 18, 1352 (1979).

${ }^{12}$ P. Chuang, J. Smith, R. Flagan, and J. Seinfeld, J. Atmos. Sci. Technol. 17, 1005 (2000).

${ }^{13}$ H. Giebl, A. Berner, G. Reischl, H. Puxbaum, A. Kasper-Giebl, and R. Hitzenberger, J. Aerosol Sci. 33, 1623 (2002).

${ }^{14}$ H. Wex, A. Kiselev, M. Ziese, and F. Stratmann, Atmos. Chem. Phys. 6, 4519 (2006).

${ }^{15}$ J. R. Snider, M. D. Petters, P. Wechsler, and P. Liu, J. Atmos. Oceanic Technol. 23, 1323 (2006).

${ }^{16}$ S. Lance, J. Medina, J. N. Smith, and A. Nenes, Aerosol Sci. Technol. 40, 242 (2006).

${ }^{17}$ D. Rose, S. Gunthe, E. Mikhailov, G. Frank, U. Dusek, M. Andreae, and U. Poschl, Atmos. Chem. Phys. 8, 1153 (2008).

${ }^{18}$ H. Köhler, Trans. Faraday Soc. 32, 1151 (1936).

${ }^{19}$ H. Smith, P. Connolly, A. Baran, E. Hesse, A. Smedley, and A. Webb, J. Quant. Spectrosc. Radiat. Transfer 157, 106 (2015).

${ }^{20}$ S. Hartmann, D. Niedermeier, J. Voigtländer, T. Clauss, R. A. Shaw, H. Wex, A. Kiselev, and F. Stratmann, Atmos. Chem. Phys. 11, 1753 (2011).

${ }^{21}$ H. Wex, S. Augustin-Bauditz, Y. Boose, C. Budke, J. Curtius, K. Diehl, A. Dreyer, F. Frank, S. Hartmann, N. Hiranuma, E. Jantsch, Z. A. Kanji, A. Kiselev, T. Koop, O. Möhler, D. Niedermeier, B. Nillius, M. Rösch, D. Rose, C. Schmidt, I. Steinke, and F. Stratmann, Atmos. Chem. Phys. 15, 1463 (2015).

${ }^{22}$ H. Lihavainen and Y. Viisanen, J. Chem. Phys. B 105, 11619 (2001).

${ }^{23}$ D. Brus, A.-P. Hyvärinen, Y. Viisanen, M. Kulmala, and H. Lihavainen, Atmos. Chem. Phys. 10, 2631 (2010).

${ }^{24}$ K. Neitola, D. Brus, U. Makkonen, M. Sipilä, H. Lihavainen, and M. Kulmala, Boreal Environ. Res. 19(Suppl. B), 257 (2014), http://www.borenv.net/BER/pdfs/ber19/ber19B-257.pdf.

${ }^{25}$ C. Clement, Proc. R. Soc. London, Ser. A 398, 307 (1985).

${ }^{26} \mathrm{H}$. Lihavainen, Finnish Meteorological Institute, in "Laminar flow diffusion chamber for homogeneous nucleation studies," Report Series in Aerosol Science No. 45 (Finnish Association for Aerosol Research, Helsinki, 2000), ISSN 0784-3496.

${ }^{27}$ R. B. Bird, W. E. Stewart, and E. N. Lightfoot, Transport Phenomena (John Wiley \& Sons, New York, 1960).

${ }^{28}$ W. D. Hall and H. R. Pruppacher, J. Atmos. Sci. 33, 1995 (1976).

${ }^{29}$ T. Raatikainen, R. H. Moore, T. L. Lathem, and A. Nenes, Atmos. Chem. Phys. 12, 4227 (2012).

${ }^{30}$ J. H. Seinfeld and S. N. Pandis, Atmospheric Chemistry and Physics: From Air Pollution to Climate Change (Wiley, New York, USA, 1998).

${ }^{31}$ N. Fukuta and L. A. Walter, J. Atmos. Sci. 27, 1160 (1970).

${ }^{32}$ M. D. Petters and S. M. Kreidenweis, Atmos. Chem. Phys. 7, 1961 (2007).

${ }^{33}$ M. D. Petters and S. M. Kreidenweis, Atmos. Chem. Phys. 8, 6273 (2008).

${ }^{34}$ G. P. Frank, U. Dusek, and M. O. Andreae, Atmos. Chem. Phys. Discuss. 6, 4879 (2006). 